\title{
"LIXO", LIMPEZA URBANA E EDUCAÇÃO AMBIENTAL NA IMPLANTAÇÃO DA COLETA SELETIVA DE LIXO EM PORTO ALEGRE
}

\author{
Wilson José Ferreira De Oliveira ${ }^{1}$
}

Há exatamente trinta anos, Porto Alegre dava início à "coleta seletiva de lixo", tornando-se uma das capitais pioneiras na implantação deste tipo de serviço. De lá para cá, algumas mudanças podem ser observadas: passou de três Unidades de Triagem para dezesseis; o percentual de "resíduos recicláveis", o "lixo seco", que era de 0,07\% em 1990 e 0,27\% em 1992 está em 5,3\% em 2020, segundo dados atuais do próprio Departamento Municipal de Limpeza Urbana (DMLU). Atualmente, a cidade possui 3 tipos de coletas regulares: a coleta seletiva, que recolhe duas vezes por semana os "resíduos recicláveis" em 19 bairros da cidade; a coleta domiciliar que recolhe três vezes por semana os "resíduos orgânicos" e "rejeitos" na porta das casas; a coleta automatizada que disponibiliza 2.400 contêineres em 19 bairros da cidade para o descarte dos "resíduos orgânicos" e "rejeitos" a qualquer hora ou dia da semana.

Sem dúvida, a adoção do programa de coleta seletiva, como era normalmente conhecido naquele momento, fazia parte de uma mudança de longa duração e implicava "mexer" com noções e valores políticos e culturais a respeito do que comumente chamamos de "lixo" e que, para não perturbar nossa "consciência", preferimos mandar para bem longe de "onde nossa vista alcance". Tal redefinição do "lixo" têm como marco inicial meados da década de 1960. É a partir desse período que os diagnósticos, os problemas e as soluções relativas à produção e ao tratamento dos resíduos sólidos passam a ser associados à problemática ambiental. Até então, no período de institucionalização dos serviços de limpeza urbana no final do séc. XIX, era a noção de "saúde pública e de saneamento do meio" que constituía uma referência dominante. Nesta perspectiva, o "lixo" era definido como um problema de saúde pública e a limpeza urbana como um serviço de controle das

1 Universidade Federal de Sergipe, Brasil. Email: etnografia.politica@gmail.com ORCID id: https://orcid.org/0000-0001-8105-8885

Iluminuras, Porto Alegre, v. 21, n. 55, p. 181-214, dezembro, 2020. 
condições de "higiene e salubridade" da cidade. Esta redefinição do "lixo", de um problema de saúde pública para um problema de proteção do meio ambiente, não ocorreu de maneira imediata nem tampouco em contraposição ou negação à antiga noção de "saneamento do meio". Todavia, ela implicou certas mudanças políticas e organizacionais na definição do papel dos serviços de limpeza urbana, de suas fronteiras institucionais, como também nos modos de lidar com esse problema público, tanto por parte dos indivíduos e consumidores quanto por parte das organizações, gestores e formuladores de políticas públicas.

A pesquisa que deu origem a esse artigo foi realizada logo após o início dessa experiência "inovadora", tomando como referencial empírico a implantação do programa de Coleta Seletiva de Lixo em Porto Alegre ${ }^{2}$. Foi através de uma imersão na gênese e no processo de institucionalização dos próprios serviços de limpeza urbana que encontrei algumas das condições sociais, políticas e culturais de possibilidade desta "novidade". Em consonância com isso, esse artigo pretende caracterizar as condições e os processos de emergência da redefinição do "lixo" como resíduo sólido e problema ambiental e suas relações com as dinâmicas de elaboração e de operacionalização do programa de coleta seletiva em Porto Alegre. Não é objetivo dele trazer informações atualizadas sobre o percurso dessa política pública ao longo destes 30 anos, indicando suas mudanças, problemas, dificuldades e desafios atuais. Outro trabalho igualmente desafiador e que requereria uma pesquisa específica, consiste em analisar o que foi produzido nas ciências sociais sobre esta experiência, não apenas em Porto Alegre, mas em diferentes cidades do estado e mesmo do país. No que pesem essas limitações que o próprio tempo se encarregou de trazer à tona, defendo que evidenciar as condições iniciais de formulação e implementação de uma política pública constitui um aspecto sempre importante para a compreensão de parte dos desafios incialmente enfrentados, como também para uma melhor avaliação de como eles foram posteriormente melhor dimensionados ou até mesmo esquecidos e, portanto, ainda persistentes em meio a tantas mudanças. Deste modo, não tenho dúvida de que os aspectos aqui demonstrados são tão atuais para a compreensão do surgimento e da evolução desta política pública quanto eram no período em que a pesquisa

2 Este texto é uma versão modificada e atualizada de uma pesquisa de mestrado (Oliveira, 1995) e de reflexões que venho desenvolvendo sobre os usos sociais da ecologia na formulação de políticas públicas (Oliveira, 2014; Nascimento e Oliveira, 2019; Nascimento, Oliveira e Souza, 2020). 
foi realizada.

\section{A Limpeza urbana, a proteção ambiental e os resíduos sólidos}

A partir de meados da década de 60, a produção e o tratamento dos resíduos sólidos passaram a ser interpretados e definidos em função dos problemas que causavam ao meio ambiente, podendo-se tomar tal período como um marco inicial do surgimento da temática ambiental no domínio da limpeza urbana no Brasil. Foi nesse período que começaram a serem introduzidas em cursos universitários matérias relacionadas aos temas lixo, resíduos sólidos, limpeza urbana, cujo exemplo principal foi o da Faculdade de Higiene e Saúde Pública da Universidade de São Paulo que criou um curso específico sobre o "lixo". Foi também nesse período que o termo "resíduos sólidos" passou a ser utilizado para classificação dos diferentes tipos de "lixo".

Um conjunto de congressos, encontros e seminários ocorreram com uma frequência quase anual a partir dos anos de 1960, possibilitando reunir os responsáveis pela limpeza urbana nas prefeituras, o pessoal técnico, bem como empresas e demais agentes interessados e vinculados à mesma. Assim, de 18 a 21 de outubro de 1965 foi realizado o seminário "O Problema do Lixo no Meio Urbano", promovido pela Organização PanAmericana da Saúde - OMS e pela Faculdade de Higiene e Saúde Pública da Universidade de São Paulo (USP). Segundo depoimentos de atores que promoveram e participaram do mesmo (dentre os quais cabe destacar Júlio Rubbo, diretor da então Divisão de Limpeza Pública de Porto Alegre, no ano de 1965 e no período de 1969-1974) e editoriais e reportagens de publicações da Associação Brasileira de Limpeza Pública (ABLP) e da Associação Brasileira de Engenharia Sanitária e Ambiental (ABES), ele é colocado como um marco inicial da própria limpeza pública brasileira, "dos serviços tecnicamente bem feitos e sanitariamente bem realizados"3. Em novembro de 1969 é realizado o "I Seminário Nacional de Limpeza Pública" patrocinado pelo então Instituto Nacional de Administração

3 Nas palavras de Júlio Rubbo (1994), um dos participantes deste e dos outros encontros. A importância em destacar esta visão sobre o período deve-se ao fato da mesma não constituir-se em algo isolado, mas ao contrário, este encontro é tomado como um marco inicial da limpeza urbana no Brasil na Revista de ABES, da ABLP e no depoimento dos demais atores que participaram deste e dos demais congressos, seminários, encontros, etc.

Iluminuras, Porto Alegre, v. 21, n. 55, p. 181-214, dezembro, 2020. 
Municipal, hoje Instituto Brasileiro de Administração Municipal (IBAM). No ano de 1970 é realizado o "II Seminário sobre o Problema do Lixo no Meio Urbano", no qual foram lançadas as bases para a constituição da Associação Brasileira de Resíduos Sólidos e Limpeza Pública (ABLP), o que veio a acontecer formalmente no ano de 1973. De 03 a 08 de março de 1974 acontece o "I Congresso Brasileiro de Limpeza Pública em Brasília"; em 1976 o II ${ }^{\circ}$, em Fortaleza, em 1978 o III ${ }^{\circ}$ em São Paulo e em 1980 o IV , em Blumenau; todos promovidos pela ABLP com o apoio de autoridades governamentais estaduais e/ou municipais. Também vinculados a ABLP aconteceram diversos encontros e seminários nacionais sobre o tema, realizados no intervalo entre os congressos. Paralelo a isto, aconteceram, ainda, os Congressos Brasileiros de Engenharia Sanitária, promovidos pela Associação Brasileira de Engenharia Sanitária (ABES) que mesmo vinculada mais diretamente aos problemas sanitários de água e esgoto, passa a incorporar o tema resíduos sólidos em seus congressos. De uma maneira geral, são questões diretamente vinculadas à administração e ao funcionamento dos serviços de limpeza urbana que começam a ser tematizados nestes congressos, encontros e seminários específicos sobre "lixo" e limpeza urbana.

Tais atividades faziam parte de um conjunto de ações voltadas para a rearticulação dos diferentes organismos responsáveis pela limpeza urbana, resultando na própria reformulação institucional da forma de gestão e administração destes serviços. Tomando como referência a então Divisão de Limpeza Pública de Porto Alegre, percebe-se que, a partir de meados da década de 60, algumas interpretações dadas ao "lixo" e às soluções apontadas para o modo de administração do serviço de limpeza urbana local vão ser influenciadas pelas discussões e debates realizados nestes encontros.

Neste sentido, no ano de 1966, o então diretor da Divisão de Limpeza Pública, Mano José, destaca a presença da mesma no seminário acima citado "O Problema do Lixo no Meio Urbano" e cita algumas recomendações em termos de organização dos serviços de limpeza urbana, como é o caso, entre alguns outros, do projeto de autarquização da então Divisão de Limpeza Pública a partir do ano de 1966. A ideia exposta em 1972, pelo então diretor Júlio Rubbo, de que o destino final do lixo deveria evitar a "poluição da atmosfera", bem como a reivindicação de que o serviço de limpeza urbana "é tão importante" quanto o 
de abastecimento de água e redes de esgoto, são questões amplamente debatidas nestes encontros. A própria participação de diferentes diretores do serviço de limpeza urbana local nestes encontros e na fundação da Associação Brasileira de Resíduos Sólidos e Limpeza Pública é significativo do grau de articulação entre estes e o serviço de limpeza urbana em Porto Alegre, assim como do papel desempenhado pelos congressos, encontros, etc., nas redefinições do "lixo" e do modo de sua administração e gestão.

A destinação do "lixo" tornou-se, assim, um dos principais desafios que dizem respeito ao próprio andamento da sociedade como um todo, constituindo-se em "sério fator de poluição ambiental" decorrente da "problemática do desenvolvimento" (urbano, industrial, etc.), uma vez que este último é fator de agravamento dos problemas relativos à geração, coleta e destinação dos resíduos sólidos. Trata-se, por um lado, da "manutenção do equilíbrio ecológico"; por outro, de problemas mais específicos como "preservação da qualidade da vida urbana", "uso de recursos naturais", "harmonização do desenvolvimento socioeconômico de uma determinada região", "controle da poluição", etc. A partir do ano de 1972, período em que pela primeira vez a "poluição da atmosfera" aparece nos relatórios da então Divisão de Limpeza Pública de Porto Alegre como justificativa para a adoção de "aterros sanitários" como a técnica adequada para destinação final do lixo coletado, a referência à proteção ambiental no modo de gestão dos serviços de limpeza urbana tornouse uma constante: "evitar problemas ao meio ambiente", "obtendo-se melhores condições ambientais", "controle da contaminação e proteção dos solos", etc. Também a concepção que se tinha dos serviços de limpeza urbana encontra-se reformulada. As referências a este serviço vão no sentido de considerá-lo como uma forma de controle da poluição causada ao meio ambiente, como um fator de salubridade do meio e, num sentido mais amplo, associase à luta pela conservação e preservação da natureza.

No entanto, o surgimento da noção de proteção ambiental como diretriz principal não implicou uma negação e substituição imediata da diretriz anterior. Antes disto, desenvolveu-se no interior de organismos internacionais e nacionais voltados ao problema da saúde pública. É gradativamente que ela passa a ser uma diretriz predominante em matéria de gestão e administração destes serviços. Além disso, ao que tudo indica, esta inovação em termos de diretrizes não teve um efeito prático imediato sobre as medidas e 
soluções adotadas para os problemas vinculados aos serviços de limpeza urbana4.

É somente a partir da criação de organismos e agências estatais e da estrutura administrativa governamental da política ambiental no Brasil, que ocorre uma clara redefinição normativa das fronteiras institucionais dos serviços de limpeza urbana em torno da noção de proteção ambiental. Associado a isso, encontra-se também a constituição de diversas associações para mobilização e representação dos interesses técnicos, profissionais e corporativos envolvidos com a administração e gestão de tais serviços.

\subsection{O "ambientalismo de Estado"}

O estabelecimento de instituições governamentais federais e estaduais responsáveis pela gestão ambiental tem início, no Brasil, na década de 70. Primeiramente, destaca-se a criação da Secretaria Especial do Meio Ambiente, fundada em 1973 e vinculada ao Ministério do Interior, tendo como objetivo: gerir, administrar e orientar o problema do meio ambiente, da poluição, controle e manutenção dos ecossistemas no país. Em segundo, a criação de órgãos ambientais estaduais cuja origem é relativamente diferenciada, encontrando-se ligados às áreas como as de saneamento, às Secretarias de Planejamento, às Secretarias de Saúde (como é o caso, por exemplo, do Rio Grande do Sul), etc. (Andreoli, 1992). É possível perceber que, a partir daí, novas iniciativas são feitas no sentido de desenvolvimento de uma política nacional de limpeza urbana e é aí que reside a importância em destacá-lo.

Uma primeira ação desenvolvida foi a produção em 1979, por interferência da Secretaria Especial do Meio Ambiente, de uma portaria ( $\mathrm{n}^{\circ}$ 53) do então Ministro do Interior Rangel Reis, que criava as primeiras diretrizes e critérios a serem cumpridos pelas municipalidades, visando ao controle da poluição ambiental em consequência da má destinação dos resíduos sólidos. Esta medida acabou não sendo absorvida devido à mudança de governo. Em segundo lugar, encontra-se o convênio firmado entre Secretária Especial do Meio Ambiente e Conselho Nacional de Desenvolvimento Urbano (ambos

4 Uma demonstração disto pode ser encontrada em Oliveira (1995: cap. III e IV, bem como em toda a parte III). 
vinculados ao Ministério do Interior) com a Associação Brasileira de Engenharia Sanitária e Ambiental, para elaboração do Programa Diretrizes Nacionais de Limpeza Urbana, lançado em 1981 no "XI Congresso Brasileiro de Engenharia Sanitária", constituindo-se como mais uma tentativa de se estabelecer uma política nacional para o setor. Este programa teve início a partir de reuniões de agentes vinculados aos serviços de limpeza urbana e aos Ministérios da Saúde e do Interior e da Secretaria de Planejamento, resultando num documento intitulado "Documento Básico para Formulação do Programa Nacional de Limpeza Urbana" dando origem ao convênio entre SEMA-CNDU em 1981 e à criação do "Projeto Diretrizes Nacionais de Limpeza Urbana". Neste projeto a ABES ficou como órgão executor da política da SEMA/CNDU.

Em 1982, no período de 29 a 31 de março, realizou-se o "I Seminário sobre Resíduos Sólidos Urbanos", promovido pela SEMA, CNDU e OPS. Neste seminário foram discutidos também vários aspectos referentes ao "Projeto Diretrizes Nacionais de Limpeza Urbana" com a finalidade de "apresentar propostas para a elaboração das Diretrizes Nacionais de Limpeza Urbana". Nos debates suscitados por este encontro, uma série de problemas são relacionadas às dificuldades encontradas pelos serviços de limpeza urbana, entre as quais ressalte-se: a ausência de uma política nacional que regulamente principalmente a disposição final dada aos resíduos sólidos; a falta de "continuidade política" na administração local dos serviços; conflitos existentes entre legislações municipais, estaduais e federais; necessidade de recursos humanos, de treinamento de pessoal e de um responsável técnico que não mudasse de função conforme as vontades de prefeito ou mudanças políticas; a dificuldade em estabelecer um sistema de "indução ou incentivo" capaz de fazer com que as municipalidades locais cumprissem as determinações em termos de legislação de controle da poluição frente ao caráter municipal da limpeza pública; o problema da "catação", do "aproveitamento" e da "reciclagem do lixo"; entre muitas outras questões que são relacionadas aos serviços de limpeza urbana.

Através de iniciativas como esta, juntamente com outras mais especificamente voltadas à criação e desenvolvimento de uma "Política Nacional do Meio Ambiente", levada a cabo pelo governo federal no começo da década de 80, as fronteiras setoriais dos serviços de limpeza urbana que, anteriormente, estavam vinculadas ao setor de saúde, 
começam a deslocar-se para organismos e instituições governamentais de proteção ambiental. Não que se tenha passado, com isto, por uma espécie de centralização ou até unificação das formas de gestão e administração da limpeza urbana. Apenas é perceptível que os organismos ambientais passaram a ter um papel normativo no que diz respeito à aprovação e até interdição dos sistemas de destino final do lixo. Em consonância com isso, as ações causadoras de poluição passam a constituir infração que requerem penalidades específicas por parte dos órgãos executores da política de proteção ao meio ambiente5.

De maneira mais diretamente relacionada aos resíduos sólidos é editado pela Prefeitura Municipal de Porto Alegre, através da Secretaria Municipal do Meio Ambiente, o decreto $n^{\circ} 9367$ de 29 de dezembro de 1988 que regulamenta a Lei Complementar $n^{\circ} 65$ de 22 de dezembro de 1981 referente ao manejo de resíduos sólidos no município. Neste decreto percebe-se com nitidez o papel normativo que é atribuído a tal secretaria, principalmente no que diz respeito à implantação de métodos de "tratamento e disposição final de resíduos sólidos".

Cabe destacar, por fim, que esta nova articulação institucional dos serviços de limpeza urbana com os de proteção ambiental não implicou uma negação do referencial de saúde pública acima destacada. No decreto 99.274 é objeto de penalidade dos organismos responsáveis pela proteção ambiental "causar poluição de qualquer natureza que possa trazer danos à saúde ou ameaçar o bem-estar"6. Do mesmo modo, no decreto da SMAM, salienta-se que os "Resíduos sólidos devem ser coletados e transportados de maneira a prevenir problemas de saúde pública, risco com a segurança e outros incômodos."7 Contudo, a nível institucional os projetos e/ou sistemas de disposição final de resíduos sólidos encontram-se sujeitos à aprovação e fiscalização de organismos públicos de proteção ambiental em conjunto com o de limpeza urbana local e não mais às antigas diretorias ou secretarias de higiene e saúde pública.

5 Ver decreto $n^{\circ} 88.351 / 83$, Título III, Das Penalidades. O decreto 99.274 de 06 de junho de 1990 que revoga o 88.351, mantém estas resoluções referentes aos resíduos sólidos e atividades causadoras de poluição do solo.

6 Ver Título III, Das Penalidades.

7 Ver Capítulo III, Seção I, art. $8^{\circ}$. 


\subsection{O associativismo das lideranças administrativas e técnicas}

Paralelamente à constituição das agências governamentais diretamente vinculadas ao domínio da limpeza urbana foram também criadas associações para mobilização e representação dos interesses envolvidos com a administração e gestão de tais serviços. Entre estas destaca-se a Associação Brasileira de Resíduos Sólidos e Limpeza Pública (ABLP) e a Associação Brasileira de Engenharia Sanitária e Ambiental (ABES)8. Para o que interessa neste artigo cabe destacar o papel desempenhado por tais associações na difusão e divulgação de modelos estrangeiros de administração destes serviços e de soluções a serem adotadas no tratamento do lixo.

Fundada no início da década de 1970, a Associação Brasileira de Resíduos Sólidos e Limpeza Pública (ABLP) era composta, fundamentalmente, por sócios individuais, de organismos públicos e de empresas privadas compactadoras e/ou empreiteiras de coleta e destino final do lixo. O indicativo de sua constituição foi tirado já no "I Seminário sobre o Problema do Lixo no Meio Urbano" de 1965, promovido pela Organização Pan-Americana da Saúde e pela Faculdade de Higiene e Saúde Pública da Universidade de São Paulo. Esta ideia será retomada durante o "II Seminário sobre o Problema do Lixo no Meio Urbano", realizado na Faculdade de Higiene e Saúde Pública da USP, e a constituição formal da mesma ocorrerá no ano de 1973. Sua fundação esteve vinculada à constituição de uma nova concepção dos serviços de limpeza urbana, do seu papel e do lugar que deveria ocupar na sociedade. Colocando em presença dirigentes e funcionários de diversos serviços de limpeza urbana, técnicos, homens políticos, representantes de organizações internacionais como a OPS, etc., tais seminários, congressos e encontros foram momentos privilegiados na construção de uma nova imagem social dos serviços de limpeza urbana, permitindo aquilo que Jobert e Muller (1987) definem como "a fusão entre os interesses setoriais-corporativos e os interesses globais" (p. 179). Tratava-se,

8 No entanto, cabe salientar que estas não são as únicas. Ainda na década de 70 é fundada a Associação Brasileira dos Empresários da Limpeza Pública (ABRELP), congregando os empresários vinculados aos serviços de coleta contratada, com o objetivo de desenvolver a cooperação entre as empresas e "pôr um fim na imagem negativa da coleta contratada". Também é destacada a participação de organismos como a CETESB (empresa de capital misto vinculada à Secretaria de Obras e Meio Ambiente do Governo de São Paulo) nas discussões e debates sobre o rumo dos serviços de limpeza urbana e na criação de uma diretoria específica de Tecnologia de Resíduos Sólidos. 
de maneira mais específica, de constituir um elo, de ligação e de orientação, na administração de tais serviços.

A criação de uma revista (Limpeza Pública) de publicação da associação também encontra-se respaldada nesta proposta de tratar de todos os assuntos relacionados com a limpeza urbana e constituir-se como uma espécie de ferramenta aos administradores locais. Tais objetivos atribuídos à ABLP encontram-se respaldados numa série de diagnósticos que salientam o caráter eminentemente local e fragmentado que teria marcado o modo de organização e de funcionamento dos serviços de limpeza urbana até então e que, em função disto, justificam a importância de uma entidade destinada a orientar os administradores, planejadores e empresários ligados à área. Isto está presente no conjunto da publicação da entidade. É o caso, entre vários outros, do editorial da revista Limpeza Pública de 19779, no qual salienta-se a "fragmentação do setor, o pragmatismo e a falta de padronização" na forma como tais serviços estavam sendo administrados. Assim, a criação da ABLP iria trazer diversos elementos para motivar profissionais e fornecer $o$ embasamento tecnológico e administrativo para o aprimoramento de sua atividade.

Tal propósito esteve, desde o início, orientado e respaldado na experiência ocorrida em países europeus e norte americanos. Estas associações estrangeiras apresentam-se muito mais do que uma simples referência geral para a criação da ABLP. Ao que tudo indica, trata-se mesmo de uma tentativa de copiar para o Brasil o mesmo modelo adotado pelos "países que já tinham experiência" neste domínio. Algumas das ações realizadas por tal associação vão ao encontro justamente do que foi acima enunciado. Ou seja, trata-se da organização de encontros, de seminários e de congressos, e da publicação de uma revista. No editorial de lançamento do primeiro número desta revista, os objetivos acima citados da ABLP (enquanto "elo de ligação dos que labutam na área") são reafirmados e a referência ao sucesso das associações estrangeiras e de suas publicações é novamente salientada. Por outro lado, no conjunto dos artigos publicados por esta revista encontram-se, de maneira quase exclusiva nos primeiros anos, os trabalhos traduzidos de revistas europeias e americanas sobre "coletas seletivas", "usinas de compostagem", "reciclagem", formas de organização dos serviços de limpeza urbana em cidades europeias, 
etc.

Ao mesmo tempo em que servia de espaço de divulgação de experiências estrangeiras para o setor, tal entidade orientou-se para a redefinição das fronteiras setoriais entre os serviços de limpeza urbana e os de saneamento básico. Neste sentido, podemos observar um conjunto de posições contrárias à marginalização e ao esquecimento da limpeza urbana no setor de saneamento básico e uma série de ações voltadas para o reconhecimento do setor como um serviço de importância destacada e que, por isso mesmo, merecia um tratamento bem mais adequado do que o que vinha recebendo até o momento pelas autoridades governamentais.

A limpeza urbana era comumente definida como um serviço de saneamento básico, mais precisamente como um dos lados do "triângulo do saneamento", cujos outros lados são compostos pelos serviços de abastecimento de água e os de redes de esgotos. No entanto, os serviços de limpeza urbana e os outros relativos ao saneamento básico não ocupavam uma mesma posição nas prioridades governamentais em matéria de saneamento 10. Por isso, as atividades e iniciativas desenvolvidas pela ABLP apresentavam-se como tentativas de redefinição da imagem veiculada dos serviços de limpeza urbana e da própria posição ocupada pelos mesmos, na hierarquia dos organismos públicos em geral e, mais especificamente, em relação ao setor de saneamento básico.

Nos encontros e seminários, nas publicações e nos depoimentos de agentes vinculados à ABLP, bem como nos relatórios do organismo local de Porto Alegre responsável pela limpeza urbana, relativos às décadas de 60/70, encontra-se de forma predominante o que poderia ser designado como uma imagem negativa destes serviços, a qual consiste, frequentemente, em denunciar o lugar marginal que vinha sendo dado pelos mesmos até então. Em geral, as posições defendidas vão no sentido de mostrar que a limpeza pública não era considerada até então como um serviço que despertasse o interesse tanto dos organismos estatais quanto de pessoal dispostos a trabalhar nos mesmos. Este lugar marginal ocupado pela limpeza urbana é colocado também como um problema que vai dificultar o recrutamento de pessoal, assim como dos próprios profissionais para o

10 Para uma demonstração disto em relação aos investimentos do Planasa nos serviços públicos de água, esgoto e limpeza urbana ver Costa (1991).

Iluminuras, Porto Alegre, v. 21, n. 55, p. 181-214, dezembro, 2020. 
exercício da função de direção dos mesmos, dado que tais serviços eram vistos como um lugar de "desterro profissional".

Esta situação de marginalização dos serviços responsáveis pela gestão e tratamento dos resíduos sólidos no Brasil no interior do próprio setor de saneamento, justifica também a necessidade de que a ele seja dado "uma maior atenção", uma importância igual a que é aplicada aos serviços de água e de esgoto, argumento esse que, foi utilizado como justificativa principal na proposta de autarquização do serviço de limpeza urbana de Porto Alegre. Não trata-se apenas de reclamar a falta de recursos orçamentários, de pessoal e equipamentos para a limpeza pública, mas de imputar como causa o esquecimento e a marginalização destes serviços, e, em consequência, de sugerir novas medidas e soluções a serem adotadas para a sua devida melhoria.

A vinculação de lideranças responsáveis pelo serviço de limpeza urbana em Porto Alegre a esta entidade é bem notável, o que parece demonstrar a influência da ABLP na difusão e incorporação desta nova concepção da limpeza urbana para este caso: participando do processo de constituição desta entidade, dos encontros, dos seminários e dos congressos promovidos pela mesma e, inclusive, utilizando os diagnósticos e soluções veiculadas nestes encontros, para respaldar ações a serem tomadas pela então Divisão de Limpeza Urbana de Porto Alegre. Dentre estes, cabe destacar, primeiramente, Mano José, que entre os anos de 1962-1968 foi diretor da então Divisão de Limpeza Pública de Porto Alegre que participou dos congressos e seminários promovidos pela entidade, chegando até a formalizar em 1975, juntamente com Glênio Perez, uma proposta para o estabelecimento da Seção Regional-Sul da ABLP. Outro caso bastante significativo é o do arquiteto Júlio Rubbo cuja vinculação com a ABLP vai aparecer de modo bem mais acentuado, principalmente através de sua participação na criação e na direção da entidade: foi seu primeiro vice-presidente, membro fundador e do conselho fiscal durante sucessivas diretorias, presidente da seção regional-sul. É durante sua gestão (1969-74) que tem início as primeiras medidas em direção à autarquização do serviço de limpeza urbana11. É significativo também o caso de Oscar de Souza Trindade (diretor do DMLU de 1975 a

11 Ver Costa (1983: 58-59). Trata-se da transformação da Divisão de Limpeza Pública em Departamento de Limpeza Pública, o que significou para este, juntamente com a ampliação do número de servidores e de alguns equipamentos, a "reestruturação e reorganização dos serviços". 
meados de 1983) que participou de uma série de encontros promovidos pela ABLP, tanto a nível nacional quanto os da seção regional-sul. Por fim, destaca-se ainda Luiz Vicente Vieira Dutra, diretor do DMLU de meados de 1983 a fins de 1985, que foi presidente da seção da ABLP do Rio Grande do Sul a partir de 1985. Estes exemplos evidenciam a certa influência da ABLP sobre o modo de gestão do serviço público de limpeza urbana de Porto Alegre: as questões debatidas nos encontros promovidos por esta associação, vão fazer-se presentes na administração local destes serviços como orientações gerais no tratamento do problema do lixo e até como propostas de organização e estruturação do mesmo.

Atuação semelhante foi o da Associação Brasileira de Engenharia Sanitária. Fundada em 1966 como subseção da Associação Interamericana de Engenharia Sanitária e Ambiental, sua criação tem como característica principal a mobilização e a representação dos interesses das elites técnicas na política de saneamento básico (Melo, 1989: 101-102). Voltada de maneira específica para os problemas relativos aos serviços de saneamento básico, ela constitui uma nova forma de "representação do setor perante os outros segmentos da economia", agrupando "tanto os segmentos ligados à indústria do setor quanto os responsáveis pelo desenvolvimento de tecnologia de saneamento no Brasil" (Mendes, 1994: 41).

Enquanto entidade voltada para o âmbito do saneamento básico, os problemas relativos à limpeza urbana não ocuparam na ABES uma posição semelhante ao lugar atribuído aos serviços de abastecimento de água e redes de esgoto. Na revista Engenharia Sanitária (órgão de publicação oficial da entidade) o conjunto das publicações são relativas à água e esgoto, enquanto que a limpeza urbana tem um lugar secundário, aparecendo ocasionalmente através da publicação de alguns artigos referentes ao tema. Do mesmo modo, nos congressos anuais por ela promovidos e consagrados à engenharia sanitária, $\mathrm{o}$ tema "resíduos sólidos" tem um lugar bem mais restrito que os demais; somente a partir de 1984 é que é criado um comitê específico para tratar de tal tema. Ocasionalmente, a limpeza urbana é referida como um dos problemas do saneamento básico, como uma tarefa da administração no campo da engenharia sanitária, dentro, portanto, do setor de saneamento. Nestas referências ocasionais à limpeza urbana salienta-se que este é o setor mais sacrificado do saneamento básico quer pela indiferença quanto pela exigência de 
recursos e de conhecimentos técnicos para sua solução.

Essa constatação do lugar secundário da limpeza urbana para a ABES não pretende minimizar todo o trabalho por ela realizado em relação à limpeza urbana. Pelo contrário, é ela quem vai ser contratada em 1981 pela SEMA e pelo Conselho Nacional de Desenvolvimento Urbano (CNDU), ambos vinculados ao Ministério do Interior, como órgão executor de sua política no "Projeto Diretrizes Nacionais de Limpeza Urbana"; projeto este que foi por ela elaborado em convênio com a SEMA e o CNDU e lançado no XI Congresso da ABES pelo referido Ministério, constituindo-se como "a primeira possibilidade de se estabelecer uma política nacional para o setor" (Mendes, 1991: 41). Enquanto instituição articuladora de interesse setoriais empresariais, ela adquiriu status quase público, quer como órgão consultivo, quer como órgão técnico de assessoramento e foi instrumental na viabilização de uma cultura técnica hegemônica que privilegiava os interesses de tais setores (Melo, 1989: 101).

Além do mais a ABES objetiva também a representação dos interesses envolvidos no domínio da limpeza urbana. É o que se percebe nas justificativas expostas sobre o lugar de liderança que ela deveria ocupar na realização de um Programa Nacional de Administração e Gerenciamento de Resíduos Sólidos (Pronagres) destinado à formação de recursos humanos para o setor de limpeza urbana, ressaltando a necessidade de que haja um "núcleo técnico" capacitado a nível nacional para organizar, coordenar e supervisionar um programa de tal porte e propondo claramente que tal encargo seja dado à mesma por uma série de motivos:

. . . sua penetração e liderança a nível nacional, prestando serviços a todo o setor de saneamento; a grande experiência acumulada em organizar, coordenar e supervisionar um programa de grande porte, como o desenvolvimento de recursos humanos em apoio ao PLANASA - Plano Nacional de Saneamento; uma gerência de Comunicação Social e Publicações estruturada; convênios em vigor com BNH, SEMA/CNDU, que poderão eventualmente ser estendidos; um Comitê de Resíduos Sólidos que reúne os mais destacados técnicos do setor; e, a existência de vice-presidência de Resíduos Sólidos nas seções regionais que cobrem todo o território nacional. (Revista Engenharia Sanitária, vol. $24, \mathrm{n}^{\mathrm{o}} 2$, abr/jun, p. 182)

Nessa defesa do seu papel de liderança nacional dos serviços de saneamento básico, aparece a menção à limpeza urbana como um dos serviços do saneamento ao lado 
dos de água e esgoto.

No que se refere ao Setor de Saneamento, os sistemas de limpeza urbana, ao lado de abastecimento de água e esgotamento sanitário, constituem-se em serviços responsáveis pela criação de condições mínimas que garantam a habitabilidade de uma cidade. (Id., p. 180)

É importante destacar a ação da ABES na medida em que, além das realizações acima citadas, é ela quem, a nível nacional, parece desempenhar atualmente o papel pretendido pela ABLP na discussão e difusão dos problemas e soluções relativos à limpeza urbana, principalmente através de seu Comitê Permanente de Resíduos Sólidos e de seus congressos anuais. Neste sentido, ela se constitui como um espaço de participação e entrosamento entre técnicos ligados ao domínio da limpeza urbana, bem como de troca e difusão de experiências administrativas desenvolvidas por organismos responsáveis por estes serviços em diferentes cidades e regiões do país, através de congressos, seminários e encontros promovidos pela mesma. O caso de Porto Alegre é um exemplo disto. Ela foi um "contato meio que natural"12 das lideranças responsáveis pela gestão dos serviços de limpeza urbana de Porto Alegre no período 1989-1993: participando do referido Comitê e dos congressos anuais promovidos pela mesma, apresentando em tais congressos alguns trabalhos desenvolvidos pelo Departamento Municipal de Limpeza Urbana.

\subsection{A temática ambiental e 0 acesso indireto de "problemas negligenciados"}

Tomando como referência o processo de institucionalização dos serviços de limpeza urbana em Porto Alegre no final do séc. XIX, percebe-se que a falta de recursos e de condições orçamentárias para a realização das atividades requeridas por tais serviços é um ponto frequentemente ressaltado pelos seus diretores (Oliveira, 1995)13. Também nos mencionados encontros e congressos sobre limpeza pública, a carência orçamentária, a falta

12 Nas palavras do então diretor do departamento do período 1989-1992 (Campani, 1994).

13 Sobre isto ver também Costa (1983) no qual a carência orçamentária e as medidas mais recentes adotadas com vistas a sua solução, no caso a autarquização, apresenta-se como a principal questão no desenvolvimento do serviço de limpeza urbana de Porto Alegre.

Iluminuras, Porto Alegre, v. 21, n. 55, p. 181-214, dezembro, 2020. 
de infraestrutura e de financiamento, etc., apresentam-se como o principal problema enfrentado na administração destes serviços: é o tema privilegiado sobre diferentes denominações ("aspectos tributários", "aspectos econômico-financeiros", "estrutura administrativa e autonomia financeira", etc.); é o problema mais recorrente nas diferentes temáticas debatidas, sendo apresentado como uma das principais dificuldades na administração dos serviços de limpeza urbana.

Enquanto o modelo organizacional de formulação de políticas de saneamento básico, em termos de abastecimento de água e de redes de esgoto, poderia ser descrito segundo uma lógica de "centralização institucional e decisória" pelo governo federal, principalmente a partir do PLANASA, que é considerado um marco na centralização da política de saneamento básico no Brasil posto que consistiu na transferência das atribuições do município para o $\mathrm{BNH}^{14}$, este não parecia ser o traço predominante do modo de organização e administração dos serviços de limpeza urbana até os anos de 1990. Ao que tudo indica, eles "ficaram de fora" também deste programa "centralizador": em primeiro lugar, a prioridade do programa foi dada de modo quase exclusivo aos serviços de abastecimento de água e redes de esgoto; em segundo, não observamos uma reestruturação do formato institucional como ocorreu nos primeiros; por fim, os serviços de limpeza urbana, continuaram como tarefa específica das administrações municipais.

Diante disto, a inserção da temática ambiental para o domínio da limpeza urbana nos anos de 1960-1970, permitiu forjar uma certa identidade e união entre um grupo de dirigentes, funcionários e técnicos vinculados aos serviços de limpeza urbana de diferentes localidades. Os próprios objetivos relacionados à criação da ABLP oferecem algumas indicações neste sentido: ela estava predominantemente voltada para propiciar certas orientações gerais em termos do modo de organização e de administração de tais serviços, para a redefinição da imagem dominante relativa à posição dos mesmos na sociedade e na hierarquia dos serviços de saneamento básico e, consequentemente, para a elaboração de uma nova concepção do papel e do lugar dos profissionais (dirigentes,

14 O Banco Nacional de Habitação, criado e 1964 após o golpe militar e extinto em 1986, foi uma empresa pública brasileira voltada para o financiamento de empreendimentos imobiliários, tornando-se também a principal instituição federal de desenvolvimento urbano. Era o gestor do Fundo de Garantia por Tempo de Serviço (FGTS), do Sistema Financeiro da Habitação (SFH), e do Sistema Financeiro do Saneamento (SFS). 
técnicos e funcionários) vinculados ao âmbito da limpeza urbana. Por outro lado, o papel por ela desempenhado em tal domínio está relacionado aos conflitos a respeito da posição que estes serviços deveriam ocupar no interior do setor de saneamento básico: oferecendo a possibilidade de construção de uma nova imagem para os mesmos, respaldando a formulação de propostas de autonomia administrativa e financeira que permitissem conferir a tais serviços um novo lugar institucional na hierarquia dos serviços governamentais.

Neste sentido, utilizando a tipologia de Hirschmann (1965), torna-se sugestivo colocar que, neste processo de incorporação da perspectiva ambiental para o âmbito da limpeza urbana, uma das funções úteis de tal temática foi a de forjar um elo causal plausível entre problemas inicialmente distintos, podendo ser vista como uma "estrutura intermediária" entre "problemas privilegiados" e "negligenciados" (Id, p. 264): "a ideologia às vezes remedeia a falta de acesso direto de certos problemas negligenciados e lhes proporciona acesso indireto através da formulação de teorias que criem elos entre os problemas privilegiados e os negligenciados".

Dito de outro modo, a temática ambiental foi um meio de se conseguir o reconhecimento para um conjunto de problemas relativos à administração e funcionamento dos serviços de limpeza urbana que eram "negligenciados" no interior do setor de saneamento básico, permitindo que eles tivessem um acesso "indireto" à agenda política e governamental, passando a ser tematizados e considerados como de "urgente solução" devido ao potencial "degradador" que a má administração de tais serviços poderia ocasionar ao meio ambiente. Deste modo, ela funcionou como uma espécie de justificativa geral que possibilitava que antigos problemas organizacionais e estruturais enfrentados na administração dos serviços de limpeza urbana, tais como carência financeira, falta de profissionalismo na área, falta de autonomia administrativa, etc., fossem colocados como prioritários em função da "gravidade e da ameaça" que os "resíduos sólidos" poderiam ocasionar para a "humanidade como um todo" quando mal administrados e inadequadamente tratados.

Nesta lógica, a aplicação de medidas imediatas e efetivas em termos de implementação de programas especificamente voltados para a resolução dos problemas ambientais causados pelo tratamento inadequado dos resíduos sólidos, não parece ter sido o 
desafio principal colocado à gestão destes serviços neste período. Antes disto, encontra-se aqui uma série de problemas "prementes" (como a resolução da "carência continuada de orçamento, pessoal e equipamento", a "fragmentação", o "isolacionismo", a "falta de planejamento", o "esquecimento e marginalização da limpeza urbana no interior do próprio setor de saneamento básico", etc.) que são apresentados nos congressos e encontros como situações "necessitando de urgente modificação" e que, com a associação entre limpeza urbana e "proteção da natureza", deverão ser agora privilegiados. Neste conjunto de "problemas" os referentes à carência financeira e falta de autonomia administrativa são os mais recorrentes: quando se fala em minimizar o "impacto ambiental causado pela má destinação do lixo" estes "outros problemas" são levantados como as questões que precisam ser anteriormente solucionadas para que se consiga "tratar o lixo adequadamente" sem causar maiores danos ao meio ambiente.

De maneira semelhante ao que ocorria no âmbito nacional, no caso dos serviços de limpeza urbana em Porto Alegre, as justificativas dadas ao projeto de transformação da então Divisão de Limpeza Pública em autarquia com orçamento próprio respaldam-se em questões bem mais específicas como "falta de verbas materiais e elementos humanos", "importância tão fundamental quanto os de água e esgotos", etc. Neste sentido, tal modificação é colocada como uma das condições fundamentais para a adoção de novas medidas e técnicas que possibilitassem o "controle da poluição" causado pelos resíduos sólidos recolhidos pela mesma.

Assim, não é somente, e principalmente, em função de disputas sobre o caráter ambiental a ser dado às formas de remoção e de destinação dos resíduos sólidos que se organizam as iniciativas supracitadas, e sim de reivindicações por verbas, orçamento satisfatório para atender às demandas de remoção do lixo, contratação de pessoal, equipamentos, etc. A temática ambiental figura, assim, como mais uma referência geral que ao lado das de "saúde pública", de "higiene", etc., são empregadas simultaneamente como justificativas na medida em que ampliam o grau de importância que deveria ser atribuída à limpeza urbana. É mais em função de uma luta contra a prioridade dada aos serviços de água e esgoto e por autonomia administrativa e financeira do que elaborando e implementando programas efetivos para o "controle da poluição" que a temática ambiental 
vai orientar e estruturar programas de ação em tal domínio.

\section{A coleta seletiva e a agregação de problemas e objetivos diversificados}

Foi nesse contexto da "ecologização" dos serviços de limpeza urbana que a reciclagem de lixo começou a ser apresentada como uma solução ambientalmente adequada para o problema dos resíduos sólidos, principalmente por propiciar uma nova maneira de destinação final dos resíduos diariamente recolhidos pelos organismos encarregados pela limpeza urbana, mesmo que sua viabilidade fosse contestada por diversas razões. Foi também associada a ela que a coleta seletiva passou a ser colocada como medida a ser adotada na gestão do "lixo". Neste sentido, a relação entre coleta seletiva e reciclagem de lixo é um dos primeiros elementos que se destaca na análise do surgimento do sistema de coleta seletiva de lixo. Contudo, o processo de definição em relação à coleta seletiva não se deu sem um longo trabalho de politização do "problema-lixo", no sentido de construção de novas interpretações do problema a ser resolvido, e de sua relação com a ação desenvolvida por agentes de diferentes organizações sociais que passam a ter interesses específicos na solução do mesmo.

Um dos primeiros aspectos a ser observado na elaboração do programa de coleta seletiva é que ela não era produto de uma formulação anterior à vitória eleitoral dos novos agentes que passaram a ocupar a direção do Departamento Municipal de Limpeza Urbana em 1989. Pelo contrário, a prioridade seria dada à construção de "aterros sanitários" em substituição aos "lixões a céu aberto" até então existentes e forma principal de destinação final do "lixo" recolhido pelo Departamento ${ }^{15}$, de modo que a reciclagem e a coleta seletiva eram apenas medidas complementares. A respeito disto vale citar que por meio do decreto 10.010 de 16 de julho de 1991 foi criada a Divisão de Destino Final como parte da estrutura organizacional do Departamento, enquanto que o chamado "setor de coleta seletiva" não passava de um dos projetos do departamento, não existindo, portanto, na estruturação do organograma oficial do DMLU. Nas palavras dos próprios atores envolvidos, tratava-se mais de adquirir "experiência" e "conhecimento" sobre a própria

\footnotetext{
${ }^{15}$ Ver sobre isto Tornquist (1992: 83-84).
} 
administração dos serviços de limpeza urbana do que aplicar um projeto previamente formulado. A "compreensão" que se tinha da administração dos serviços de limpeza urbana não estava desenvolvida de modo a que se pudesse formular uma proposta "alternativa" em cima da possibilidade que se apresentava a nível institucional. Tratava-se, acima de tudo, de "conhecer o problema".

Sendo assim, o que se fez, inicialmente, foi desenvolver "experiências-pilotos" em algumas vilas da cidade, baseados mais em experiências desenvolvidas em outros trabalhos anteriores à entrada no DMLU do que na experiência institucional já existente. Estas experiências foram, a princípio, realizadas como parte de trabalhos desenvolvidos em vilas e voltados principalmente para a implantação de coleta de "lixo" nestas áreas onde este serviço não existia ainda, como é o caso da Vila Juliano Moreira e da Vila Elisabeth. $\mathrm{Na}$ primeira, mais do que na segunda, fica claro o quanto a implantação da "seletiva" (designação comum da coleta seletiva no DMLU) esteve orientada pelo e para o trabalho comunitário e motivada até por disputas políticas entre governo do Estado que queria desapropriar a Vila e Administração Municipal a quem os moradores tinham recorrido "pedindo ajuda". Dessa forma, tais experiências eram utilizadas para resolver "problemas antigos" como o da coleta de lixo em vilas. Neste caso, a motivação para "resolver problemas do Departamento" (e até da vila) era tanto mais acentuada que a de desenvolver a reciclagem de resíduos sólidos e acabavam sendo paralisadas por "falta de noção do todo", "deficiências operacionais", "falta de entrosamento e sincronia" com o próprio Departamento. Deste modo, a política de coleta seletiva adotada pelo Departamento a partir de julho de 1990 não representou uma continuidade institucional com o que vinha sendo desenvolvido em termos de política de reciclagem de lixo. Pelo contrário, com a implantação do programa de coleta seletiva o que se constatou é que a reciclagem via usinas foi relativamente abandonada enquanto a prioridade passou a ser a ampliação do sistema de coleta seletiva de lixo.

Em contraponto à própria "falta de experiência" e "conhecimento" a respeito da coleta seletiva, o recurso às experiências de coleta seletiva de outras localidades tornaramse ingredientes importantes para compensar essa "falta de bagagem", "falta de experiência em lixo", para "capacitar" e trazer "informações" aos formuladores. Neste sentido, elas 
constituíram uma espécie de ponto de partida em relação aos quais vai se delineando o modo de funcionamento do sistema a ser implantado, bem como algumas diretrizes que orientarão o projeto. Por fim, a referência a estas outras experiências não se limitam ao momento de aprendizagem para implantação do sistema na cidade, sendo tomadas como referência também quando se trata de apresentar tal programa, como eram os casos das experiências realizadas em cidades dos chamados "países desenvolvidos" (como por exemplo na Alemanha, e nos EUA) que eram sempre tomadas como referências e inspiradoras destas iniciativas. Isto evidencia, em certa medida, que uma das formas de propagação de políticas de coleta seletiva foi espécie de "contaminação" de diferentes experiências internacionais e locais.

Foi somente após um longo trabalho de redefinição do "problema-lixo" que ocorreu uma clara modificação na orientação dada à política de reciclagem. $\mathrm{O}$ trabalho de reinterpretação não decorreu apenas da ação desenvolvida por um grupo específico (no caso os "ecologistas") sobre outro (os agentes vinculados à Administração Popular), e sim do confronto e confluência de interesses entre grupos com objetivos e concepções divergentes sobre o que fazer com o "lixo" recolhido pelo DMLU, dentre os quais se destacam outros organismos públicos municipais e estaduais e um grupo específico ligado às Comunidades Eclesiais de Base que trabalhava com a "população que vivia do lixo". Se ela implicou a associação da dimensão ecológica à problemática do lixo, isso se deu mediante a agregação de objetivos e interesses novos à ideia de proteção do meio ambiente.

Desse modo, nesse processo de politização do "problema-lixo", a noção de proteção ambiental continuou a funcionar como uma espécie de "elo causal" entre "problemas antigos" do setor, permitindo sua integração na gestão dos serviços de limpeza urbana e, particularmente, na elaboração e implementação de programas destinados à solução do problema da destinação final do lixo. Por um lado, vinculando-se a "prática de catação" e o "resgate social da população marginalizada" a "sobrevivência do planeta", por outro, associando-se a "participação" e "responsabilização do cidadão" no sistema de coleta seletiva à economia de recursos, redução do impacto ambiental causado pelo "lixo", etc.

Tal processo teve como marco inicial a constituição na Câmara de Vereadores do Município uma Comissão Especial, em janeiro de 1989, com o objetivo de estudar a

Iluminuras, Porto Alegre, v. 21, n. 55, p. 181-214, dezembro, 2020. 
problemática da disposição final do lixo, em geral, na cidade de Porto Alegre e, inclusive, apontar alternativas em termos de disposição final do mesmo. Esta comissão é constituída a partir do requerimento do então vereador João Antônio Dib (ex-prefeito da cidade no período: 1983-1985) e contou com a participação de vereadores anteriormente ligados aos serviços de limpeza urbana. Além de reuniões sobre o tema, as atividades desenvolvidas por esta comissão consistiram em visitas ao Hospital da PUC e Sanatório Partenon para avaliar o tratamento dado ao lixo hospitalar, à Cooperativa dos Catadores da Ilha Grande dos Marinheiros, ao aterro sanitário da Zona Norte, aterro da Zona Sul e usina de reciclagem e a elaboração de um relatório final. Nesta comissão já podemos perceber que um conjunto relativamente amplo de agentes e entidades estavam envolvidos na discussão e na busca de soluções para o problema da destinação final do lixo: de um lado, a sugestão de agregar usina de reciclagem ao trabalho realizado pela Cooperativa dos Catadores (“começa a se resolver com isso um problema social”); de outro, a ênfase na necessidade das pessoas assumirem "a sua parte de responsabilidade sobre o lixo" que elas produzem. Ainda no início do ano de 1989 é criado também, por designação do então Prefeito Olívio Dutra a partir de negociações entre agentes das Comunidades Eclesiais de Base e do DMLU, um Fórum, neste último, para discutir a política de destino final a ser adotada para os resíduos sólidos recolhidos pelo Departamento. Deste grupo participavam agentes vinculados à METROPLAN, à Secretaria Municipal da Indústria e Comércio, à Secretaria Municipal do Meio Ambiente, à Fundação Estadual de Proteção ao Meio Ambiente, ao DMLU, à Associação Gaúcha de Proteção ao Ambiente Natural e às Comunidades Eclesiais de Base (através do Grupo de Apoio às Mulheres Papeleiras) que estavam desenvolvendo um trabalho junto aos "papeleiros e catadores de lixo", bem como assessorias de vereadores "petistas-ecologistas" da Câmara Municipal. Por fim, no final deste mesmo ano o seminário intitulado "O Lixo Como Instrumento de Resgate Social”, promovido pela Associação de Ex-Bolsistas da Alemanha (AEBA/RS), patrocinado pelo Instituto Goethe e realizado nos dias 2, 3 e 4 de outubro de 1989, que é tomado como um marco nesta mudança de rumo da política de limpeza urbana da Administração Popular.

Todavia, foi no contexto "de uma realidade em crise" que o projeto de coleta seletiva começou a ser divulgado para a população como uma solução ambientalmente 
adequada para o "problema-lixo". Trata-se, mais especificamente, da decretação, pela Prefeitura, de "estado de calamidade pública" no dia 03 de maio de 1990, em decorrência de a população local ter interditado o acesso dos caminhões do DMLU ao então "lixão" Olaria Brasil na Zona Sul. Seria o início de uma série de discussões publicamente relatadas pelos jornais e redes de televisão locais sobre a solução a ser dada para o "lixo" da cidade. Foi enquanto alternativa e solução para os problemas causados pela destinação inadequada destes resíduos, que a coleta seletiva foi apresentada para a população da cidade, seja na imprensa, em correspondências emitidas e em materiais de divulgação produzidos pelo próprio Departamento referentes a este período. Associado a esse "estado de calamidade pública" é lançada uma campanha de conscientização da população para a limpeza urbana cujo enfoque central foi no sentido de apresentar a "cota de responsabilidade de cada um pelo lixo que suja a cidade". Vemos aqui, de maneira bem clara, que a "responsabilização do cidadão" passa a ser utilizada como ingrediente para o bom funcionamento dos serviços de limpeza urbana, justificando-se que "não é a Prefeitura que suja a cidade, ela apenas tem a obrigação de limpar". Nesta mesma direção, destaca-se a aprovação por unanimidade na Câmara Municipal de Vereadores de Porto Alegre, em setembro de 1990, do Código Municipal de Limpeza Urbana que foi elaborado como um dos mecanismos mais rápidos e eficientes para a "participação e colaboração dos cidadãos".

Semelhante ao que ocorreu no momento inicial de inserção da temática ambiental no domínio da limpeza urbana, estes diferentes eventos evidenciam a continuidade do referencial ambientalista como uma espécie de "estrutura intermediária", no sentido de Hirschmann (1965), ou seja, destinado a propiciar um elo plausível entre o "problema do destino a ser dado ao lixo" e o "problema do que fazer com a população marginalizada que sobrevive da catação de lixo". Além da introdução deste "conceito de resgate social na problemática do lixo", outro argumento que respaldou este processo foi o de "responsabilização do cidadão", que pode ser tomado também como marca destacada tanto na Comissão da Câmara quanto no Fórum do DMLU acima referidos. Estes dois argumentos associados ao de proteção ambiental, são elementos chaves que vão marcar em larga medida o processo de implementação do programa de coleta seletiva que passa a substituir o sistema de reciclagem via usinas. Eles indicam também o quanto a decisão em 
relação à coleta seletiva ocorreu mediante um longo processo de redefinição das soluções que deveriam ser dadas ao "lixo", conforme o conjunto de entidades e agentes que passam a ter interesses em relação ao mesmo. Neste sentido, eles apresentam-se também como polos aglutinadores de agentes e interesses em relação à política de reciclagem via coleta seletiva que será implementada pelo Departamento.

No tocante ao polo dos agentes do DMLU tal programa constituía um "meio de conscientização ambiental": a educação ambiental da população, mais do que o reaproveitamento e reciclagem do "lixo" produzido, era o objetivo principal. A mudança de "hábito cultural" ou, em outros termos, a educação ambiental da população é o principal objetivo perseguido pelos agentes do DMLU responsáveis pela implantação deste programa. Inclusive, pode-se dizer também que para estes, a "educação ambiental" é o argumento principal a partir do qual se prioriza a coleta seletiva em relação à reciclagem via usinas. Tratava-se mais do que tudo (entenda-se mais do que reciclagem) de “conscientizar a população para o problema lixo", de "sensibilizá-la", de atingi-la, de comprometê-la. A possibilidade de "responsabilização do cidadão na gestão do problema lixo" é uma diretriz fundamental em torno da qual estes agentes vão justificar a implantação da mesma, de modo que na hierarquia dos objetivos que orientam as práticas destes agentes, o de "responsabilização do cidadão" vem quase sempre antes do de "proteção ambiental". Por outro lado, o acento dado ao "comprometimento da população" esteve associado a uma compreensão da coleta seletiva mais como um "meio de educação ambiental" do que como um programa cuja finalidade fosse a reciclagem do lixo.

Em se tratando do polo dos que defendiam o "resgate social", a situação não era muito diferente, posto que mais do que a reciclagem do "lixo" produzido, o principal objetivo da coleta era justamente constituir um "meio" para melhoria das condições de vida e de trabalho dos catadores e papeleiros". Isto pode ser visto tanto na imprensa quanto no próprio material formulado pelos agentes do Departamento encarregados da implementação da coleta seletiva, tais como folhetos para divulgação (“Quanto mais você separar, mais associações serão criadas e mais pessoas estarão empregadas”), palestras, vídeos, etc. Neste sentido, o "resgate social" é uma marca destacada na elaboração e implementação deste programa. Fundados nesta ideia de "resgate social" uma série de agentes de organizações 
sociais interessadas na coleta seletiva passam a intervir nesta política ainda que sua ação não esteja inicialmente voltada para os problemas da limpeza urbana. Aqui "reciclagem", "ecologia", "lixo", etc., são vistos como instrumentos tanto para o "resgate social desses excluídos”, quanto para a realização de um trabalho comunitário, ou seja, como uma destas lideranças mesmo afirmou, "lixo é para organizar povo". No que diz respeito à "questão ecológica" ela torna-se, como já se disse, um simples elo plausível entre os "problemas da marginalidade e da exclusão social" e os relativos à limpeza urbana. Sendo assim, a "ecologia" é a "grande chance dos papeleiros"; os "catadores e papeleiros é que são os ecólogos por excelência", pois antes mesmo que se pensasse em organizá-los "esse pessoal miserável já fazia a coleta seletiva". Objetivos como "limpeza da cidade", "ecologia", são colocados em segundo plano em função de um trabalho que solucione os "problemas ligados à pessoa do catador e papeleiro" e que proporcione a "recuperação de sua dignidade".

Deste modo, podemos falar do programa de coleta seletiva como uma política regulamentar no sentido de que a "responsabilização e comprometimento" da população com a "problemática ambiental lixo" (e, consequentemente, com a gestão da limpeza urbana) constitui a diretriz principal dos formuladores de tal política, mais do que a adoção da reciclagem do lixo domiciliar com vistas à solução do problema da destinação final dos resíduos sólidos. Dito de outro modo, sua característica principal foi mais no sentido de orientar o comportamento da população em relação ao "problema-lixo" do que no de mudar a orientação da política de destinação final implementada pelo Departamento. Ao mesmo tempo, o enfoque no "resgate social" das populações marginalizadas nos remete para a dimensão redistributiva e de inclusão social desta política, na medida em que possibilita o resgate e a organização de uma categoria há muito tempo marginalizada e excluída socialmente.

Deste modo, tanto para os agentes do DMLU encarregados pela elaboração e implementação deste programa quanto para aqueles vinculados ao Grupo de Apoio aos papeleiros que participaram da formulação e execução do mesmo, a coleta seletiva não tinha como objetivo imediato resolver o problema da destinação final do lixo produzido na cidade. Em ambos os grupos encontra-se uma espécie de concepção instrumentalista da 
coleta seletiva. Neste sentido, era comum ouvirem-se os entrevistados dizerem que "a coleta seletiva é também meio para outras questões que não só a reciclagem”. Por estas e outras conotações percebe-se o quanto a questão ambiental do lixo não era o "problema" prioritário que se buscava resolver. Como poderíamos dizer, são "problemas de outros domínios" (desemprego, marginalização, trabalho de organização comunitária, etc.), mas que passam a fazer parte do leque de problemas relativos à administração dos serviços de limpeza urbana.

\section{Conclusões}

A partir de meados da década de 60 , os problemas relativos à produção e tratamento dos resíduos sólidos passam a ser associados à temática ambiental, podendo-se tomar tal período, como uma espécie de marco temporal do surgimento do referencial ambientalista no domínio da limpeza urbana e, deste modo, do próprio processo de ecologização destes serviços. Inicialmente, no período de institucionalização da limpeza urbana (final do séc. XIX) foi a noção de "saúde pública e de saneamento do meio" que apresentava-se como uma referência dominante. Nesta perspectiva, o "problema-lixo" era definido como um problema de saúde pública e de saneamento e a limpeza urbana como um serviço de controle das condições de "higiene e salubridade" da cidade.

É a partir de meados da década de 60, que a noção de "lixo", como um problema ambiental, começa a se fazer presente cada vez mais nos relatórios anuais do serviço de limpeza urbana. Ao que tudo indica, esta redefinição do problema-lixo não se deu de maneira imediata nem também em contraposição ou negação à antiga noção de saneamento do meio. Todavia, a partir deste período, verifica-se uma certa mudança tanto na definição do papel dos serviços de limpeza urbana quanto das fronteiras institucionais destes com o chamado ambientalismo de Estado.

Neste primeiro momento, o processo de institucionalização do referencial ambientalista enquanto diretriz orientadora da ação governamental em matéria de limpeza urbana, não se deu sem um conjunto de conflitos acerca do próprio lugar ocupado por estes serviços no setor de saneamento básico e segundo objetivos específicos de construir uma 
nova imagem para os mesmos e de lhes conferir um novo lugar institucional na hierarquia dos serviços governamentais. Nesta ótica, o referencial ambientalista era apresentado mais como uma "nova interpretação" do problema-lixo e do lugar social e institucional que deveria ocupar os serviços de limpeza urbana do que o objeto dos conflitos, das mobilizações e iniciativas levadas a cabo neste período. É em torno de reivindicações por verbas, por "orçamento satisfatório para atender às demandas por lixo", de lutas pelo reconhecimento destes serviços como de igual importância aos de água e esgoto, etc., que encontramos o princípio articulador destas mobilizações. Deste modo, a proteção do meio ambiente aparece como "mais uma" diretriz, ao lado de "saúde pública", "higiene”, empregada como justificativa na luta contra a marginalização da limpeza urbana e que requeria que "velhos problemas" administrativos e financeiros fossem resolvidos.

Neste sentido, e considerando-se este contexto de ecologização da limpeza urbana, pode-se dizer que esta funcionou como uma espécie de justificativa geral que possibilitava que antigos problemas organizacionais e estruturais enfrentados na administração destes serviços (carência financeira, falta de profissionalismo na área, falta de autonomia administrativa, etc.) sejam colocados como prioritários devido à grave “poluição e degradação ambiental” que os resíduos sólidos poderiam ocasionar quando mal administrados e inadequadamente tratados. Lembrando aqui a tipologia de Hirschmann (1965) entre "problemas negligenciados e privilegiados", vimos que, neste processo de institucionalização de uma definição ambientalista do "problema-lixo", a noção de proteção ambiental parece ter servido como uma espécie de "elo causal" onde problemas antes negligenciados passam a ser tematizados e considerados como de "urgente solução" devido ao potencial "degradador” que a má administração dos serviços de limpeza urbana poderia ocasionar ao meio ambiente.

No processo de implantação do sistema de coleta seletiva fica mais evidente como o referencial de proteção ambiental foi utilizado para justificar a implantação de uma política específica. Levando em consideração os agentes que são os responsáveis pela elaboração e implementação de tal programa, bem como o modo como são recrutados para o exercício de tal função, fica nítido que não se trata de "profissionais devotados" ao domínio da limpeza urbana. Seu recrutamento não se deu em função de "critérios 
profissionais", melhor dito, não foi calcado na experiência profissional que estes tinham em relação à matéria "lixo", limpeza urbana, coleta seletiva. Mas sim, em função de sua "experiência de militância", sua "filiação" e até "simpatia" em relação a organizações políticas como Partido dos Trabalhadores e "Movimento Ecologista". Foi a partir disto que os mesmos foram indicados ou convidados a fazer parte do quadro do DMLU responsável pela implementação da coleta seletiva. Neste sentido, a lógica profissional não parece ter sido a dominante na elaboração e implementação deste programa.

Algo semelhante ocorreu no âmbito das organizações sociais que passam a fazer parte da rede institucional responsável pela implementação do referido programa. É a partir de afinidades de interesses "político partidários" e "ideológicos" entre as lideranças destas organizações que estas passam a participar do referido processo de elaboração e implementação de tal política. É o caso, por exemplo, do Movimento Ecologista e, notadamente, do Grupo de Apoio às Mulheres Papeleiras que é formado, basicamente, por militantes e lideranças do Partido dos Trabalhadores. É desta forma que novos problemas, agentes e organizações sociais passam a fazer parte da administração dos serviços de limpeza urbana.

Como resultado disto ocorre uma agregação de organizações e interesses bastante diversificados na condução deste programa. As principais disputas entre as organizações encarregadas pela operacionalização deste programa (DMLU e Grupo de Apoio às Mulheres Papeleiras) estavam voltadas mais especificamente para problemas políticos e partidários (como, por exemplo, o conflito sobre quem deve realizar "o trabalho de organização popular") do que para questões técnicas e administrativas relativas à execução do próprio sistema de coleta seletiva. Assim, embora a coleta seletiva seja constantemente referida à proteção ambiental na medida em que possibilita a "reciclagem", ou seja, a "reintrodução no ciclo industrial (produtivo)" dos elementos comumente descartados como "lixo", esta não parece ser a finalidade principal que se persegue com a implantação deste sistema. Considerando-se os agentes que participaram da elaboração e implementação do programa de coleta seletiva em Porto Alegre, percebe-se que ele tem sido objeto de formulações de organizações sociais diversas, cujo trabalho não estava inicialmente voltado para a gestão do "problema-lixo", nem tampouco para o domínio da 
limpeza urbana.

No tocante às diretrizes que respaldaram a elaboração e implementação de tal programa estão, além do referencial ambientalista, uma multiplicidade de definições que a ela se encontram agregadas. Por um lado, a coleta seletiva constituiu um meio de resolver o "problema da geração e destinação final dos resíduos sólidos", por outro, um meio de "comprometer a população com a gestão da limpeza urbana", sendo também considerada como uma forma de "resgate social dos pobres e marginalizados", ocorrendo oscilações, em certa medida, as mais variadas em cada uma destas três definições gerais. Deste modo, a noção de proteção ambiental tornou-se, ora um instrumento de luta contra a "falta de consciência ambiental" do cidadão diante de suas responsabilidades enquanto "produtor de lixo", ora, transformou-se na "grande chance dos marginalizados resgatarem sua cidadania, sua dignidade". Sendo assim, o que tem sido chamado de referencial ambientalista constituiu unicamente uma espécie de referência geral comumente aceita por todos, mas com significados os mais variados conforme a organização e os agentes que se trate, inclusive podendo-se até falar em ausência de definição comum dos significados deste programa para estes agentes e organizações responsáveis pela sua implementação e operacionalização. Isso porque o que havia era uma espécie de "compreensão difusa" (Hirschman, 1965) do programa de coleta seletiva na medida em que os objetivos e finalidades a ele associados não se restringem à resolução de um aspecto em específico dos problemas referentes à administração da limpeza urbana, mas, ao contrário, são problemas os mais diversificados que se procura com ele solucionar.

Essa compreensão difusa do programa e as "largas oscilações ideológicas" que exibem as justificativas dadas ao mesmo, não seriam apenas em função do próprio caráter "pega tudo da ecologia", da "ambiguidade e indefinição" vinculadas ao princípio de proteção e defesa da natureza. Pelo contrário, esse caráter "difuso" e até polissêmico nas interpretações e justificativas dadas ao referido programa diz respeito a certas características próprias do modo de organização e administração do serviço de limpeza urbana (recrutamento dos responsáveis pelo programa, seleção das organizações que passam a participar de sua implementação e operacionalização, modo de definição dos "referenciais" que respaldam tal política, etc.) e não somente às definições ideológicas 
utilizadas para respaldarem as políticas neste domínio. Isso porque trata-se de um domínio no qual as instituições administrativas e burocráticas são fortemente impactadas pelas mudanças políticas e eleitorais, exteriores aos grupos profissionais do setor, como também por clivagens político-ideológicas vinculadas à dinâmica político partidária e eleitoral. Deste modo, mais do que disputas em torno de um determinado referencial por grupos profissionais sobre um tal domínio, o que caracterizava tal universo eram a incorporação e "agregação" de definições e de organizações sociais diversas, em função de afinidades de interesses e compromissos político partidários e ideológicos entre os agentes interessados em tal política.

Sem dúvida, essa compreensão difusa do problema-lixo e o uso instrumental do referencial ambientalista, seja como forma de ampliar o papel e lugar dos serviços de limpeza urbana, seja como instrumento para uma maior "conscientização ambiental", constituem os ingredientes principais do processo de formulação e implementação desta política pública. Tratava-se, portanto, de uma política regulamentar de "conscientização" da população, agregando problemas diversificados, e não da adoção da reciclagem do lixo domiciliar como forma de tratamento final do lixo gerado na cidade. Talvez, tais aspectos sejam relevantes, ainda hoje, para entender porque 30 anos após sua implantação, o percentual de "lixo sexo" coletado ainda esteja em 5,3\%, enquanto que o volume de resíduos que são destinados ao aterro sanitário aumenta a todo instante. 


\section{REFERÊNCIAS}

ANDREOLI, Cléverson Vitório. Principais Resultados da Política Ambiental Brasileira: o setor público. In Revista de Administração Pública, Rio de Janeiro, no 26 (4), p. 10-31, 1992.

CAMPANI, Darci B. Entrevista concedida pelo Diretor do Departamento Municipal de Limpeza Urbana de Porto Alegre do período 1989-1992. Porto Alegre, 13 dez 1994.

CONGRESSO BRASILEIRO DE LIMPEZA PÚBLICA, $1^{\circ}, 1974$, Brasília. Anais do $1^{\circ}$ congresso brasileiro de limpeza pública. Brasília, ABLP, 1974.

CONGRESSO BRASILEIRO DE LIMPEZA PÚBLICA, $2^{\circ}, 1976$, Fortaleza. Anais do $2^{\circ}$ congresso brasileiro de limpeza pública. Fortaleza, ABLP, 1976. 93 p.

COSTA, Nilson do Rosário. Política Pública, Ambiente e Qualidade de Vida: revisitando o planasa. In Revista de Administração Pública, Rio de Janeiro, 25 (2), p.: 31-9, 1991.

COSTA, Telmo Cardoso. Histórico dos Sistemas de Água e Esgotos da Cidade de Porto Alegre: 1879-1981. Porto Alegre. PMPA-DMAE, 1981.

COSTA, Telmo Cardoso. Pequena História da Limpeza Pública na Cidade de Porto Alegre. Porto Alegre, DMLU-Assessoria de Comunicação Social, 1983.

DEPARTMENTO MUNICIPAL DE LIMPEZA URBANA. Diretrizes do Plano Diretor de Meio Ambiente e Saneamento: Resíduos Sólidos. In.: Os Caminhos do Lixo: Da Origem ao Destino Final: experiência popular de gerenciamento integrado em Porto Alegre / RS. Trabalhos Apresentados no I Simpósio Latino-Americano de Resíduos Sólidos em São Paulo, em agosto de 1993. Porto Alegre, DMLU.

DEPARTMENTO MUNICIPAL DE LIMPEZA URBANA. Gerenciamento Integrado de Resíduos Sólidos de Porto Alegre. In.: Os Caminhos do Lixo: Da Origem ao Destino Final: experiência popular de gerenciamento integrado em Porto Alegre / RS. Trabalhos Apresentados no I Simpósio Latino-Americano de Resíduos Sólidos em São Paulo, em 
agosto de 1993. Porto Alegre, DMLU.

DEPARTAMENTO MUNICIPAL DE LIMPEZA URBANA. "Lixo Pra Cá Lixo Prá Lá". (s/d). Porto Alegre. DMLU.

ENGENHARIA SANITÁRIA. Revista Bimestral da Associação Brasileira de Engenharia Sanitária. Rio de Janeiro, nº 1, 1972.

EQUIPE DE COLETA SELETIVA. (1990). Projeto de Coleta Seletiva na Cidade de Porto Alegre. Porto Alegre, DMLU.

EQUIPE DE COLETA SELETIVA. (1991). Projeto de Coleta Seletiva do Lixo Urbano. Porto Alegre, DMLU.

EQUIPE DE COLETA SELETIVA. (1992). Projeto de Coleta Seletiva de Lixo em Porto Alegre "Lixo Reciclado, Meio Ambiente Poupado". Porto Alegre, DMLU.

EQUIPE DE COLETA SELETIVA. (1993). Coleta Seletiva de Lixo no Município de Porto Alegre: uma experiência de educação ambiental. In.: Os Caminhos do Lixo: Da Origem ao Destino Final: experiência popular de gerenciamento integrado em Porto Alegre / RS. Trabalhos Apresentados no I Simpósio Latino-Americano de Resíduos Sólidos em São Paulo, em agosto de 1993. Porto Alegre, DMLU.

EQUIPE DE COLETA SELETIVA. (1995). Acompanhamento Operacional da Coleta Seletiva: demonstrativo geral ano de 1994. Porto Alegre, DMLU.

HIRSCHMAN, Albert O. Solução de Problemas e Formação de Políticas: haverá um estilo latino-americano? In HIRSCHMAN, A. O. Política Econômica na América Latina. Rio de Janeiro, Fundo de Cultura, 1965, p. 259-284.

JOBERT, B. et MULLER, P. L'Etat en Action: politiques publiques et corporatismes. France, PUF, 1987.

MELO, Marcus André B. C. de. O Padrão Brasileiro de Intervenção Pública no 
Saneamento Básico. In Revista de Administração Pública, Rio de Janeiro, 23(1), p. 84-102, 1989.

MENDES, Carlos Henrique A. Implicações Ambientais do Desenvolvimento da Infraestrutura: saneamento urbano. In Revista de Administração Pública, Rio de Janeiro, 26(4), p. 32-51, 1992.

NASCIMENTO, Mayara S.; OLIVEIRA, Wilson José. F. de; SOUZA, Moisés C. "Avanço da Maré”, Riscos Ambientais e Estado. Revista TOMO, n. 36, p. 111-146, 2 fev. 2020.

OLIVEIRA, Wilson José F. de; NASCIMENTO, Mayara S. Arenas públicas, atores sociais e saber técnico na formulação de políticas ambientais. Mediações - Revista de Ciências Sociais, v. 24, n. 1, p. 259-283, 10 maio 2019.

OLIVEIRA, Wilson José F. de. A Utilização do "Referencial Ambientalista" como Justificativa à Implantação do Sistema de Coleta Seletiva de Lixo em Porto Alegre. Dissertação (Mestrado em Sociologia) - Instituto de Filosofia e Ciências Humanas, Universidade Federal do Rio Grande do Sul, Porto Alegre, 1995.

OLIVEIRA, Wilson José F. de. De gente de cor a quilombolas: desigualdades, religião e identidade. Caderno CRH, v. 26, n. 67, p. 139-156, abr. 2013.

REVISTA LIMPEZA PÚBLICA. Publicação trimestral da Associação Brasileira de Resíduos Sólidos e Limpeza Pública, nº 1, 1975.

RUBBO, Júlio. Entrevista concedida pelo Diretor do Departamento Municipal de Limpeza Urbana de Porto Alegre do período 1969-1974. Porto Alegre, 22 dez 1994.

SEMINÁRIO SOBRE RESÍDUOS SÓLIDOS URBANOS: ASPECTOS INSTITUCIONAIS E DE PLANEJAMENTO, 1º, 1982, Brasília. Anais do $1^{\circ}$ seminário sobre resíduos sólidos urbanos: aspectos institucionais e de planejamento. Brasília, SEMA/CNDU/OPS, 1982. 639 p.

SEMINÁRIO O LIXO COMO INSTRUMENTO DE RESGATE SOCIAL, 1989, Porto 213

Iluminuras, Porto Alegre, v. 21, n. 55, p. 181-214, dezembro, 2020. 
Alegre. Anais do seminário o lixo como instrumento de resgate social. Porto Alegre, Instituto Goethe, 1989. 175 p.

SIMPÓSIO LATINO-AMERICANO DE RESÍDUOS SÓLIDOS, 1º, 1993, São Paulo. Anais do $1^{\circ}$ seminário latino-americano de resíduos sólidos. São Paulo, AIDIS, 1993.

TORNQUIST, Carla S. O Planeta e o Quintal: o movimento ecológico frente à administração popular em Porto Alegre. Dissertação (Mestrado em Sociologia Política) Centro de Filosofia e Ciências Humanas, Universidade Federal de Santa Catarina, Florianópolis, 1992.

Recebido: $24 / 09 / 2020$

Aprovado: 08/12/2020

Iluminuras, Porto Alegre, v. 21, n. 55, p. 181-214, dezembro, 2020. 